\title{
Experimental Research on Seismic Performance of Rigid Joint Between Steel Beam and Concrete Wall
}

\author{
Li Guo and Xianglan Li
}

Nanchang Key Laboratory of Material and Structure Detection, Jiangxi University of Technology

Keywords: Steel Beam; Concrete Wall; Rigid Joint; Seismic Performance; Fiber Grating Sensor

\begin{abstract}
In recent years, steel-concrete composite structure has been widely applied in high-rise buildings of China, recent related studies mainly focus on the relative displacement between the structure layer control of the structural system under the seismic effect and structural failure type under the rare earthquake action, but there is sufficient comprehensive research on seismic weak position of the structural system (such as the joint between steel frame beam and reinforced concrete core-tube). Based on previous studies, this paper combines with the practical situation in China, carries out low-cycle reversed loading test on three specimens of rigid joints between steel beam and concrete wall, compares the bearing capacity with the seismic performance under the low-cycle reversed loading test, and this paper makes experimental research and theoretical analysis of the failure form, hysteretic curve features, rigid change, yield load, ultimate load, failure load, ductility, energy-dissipating capacity, strain distribution of key parts and forces in the joint core region of three node specimens.
\end{abstract}

\section{Introduction}

Before the 1980s, most of the high-rise building structures adopt the reinforced concrete structure. However, with the rapid economic development in China, high-rise buildings that have been built and will be built increase, high-rise buildings develop toward the direction of complex body and versatile functions, and the traditional reinforced concrete structure cannot fully meet the demands on building height and use function. Therefore, based on the mature domestic reinforced concrete structure theory and design experience and combined with domestic and foreign achievements and design methods in steel-concrete composite structure, people develop a new structural type steel-concrete composite structure and widely use it in high-rise buildings.

Various loads and actions borne by bearing structure in high-rise buildings can be grouped into two categories: vertical downward load and action; and horizontal load and action. The former includes the structural weight, floor system or roof dead loads, service loads and vertical earthquake action, whereas the latter includes wind loads, seismic loads and other horizontal loads. In addition to compliance with bearing capacity requirements, high-rise building structural system should meet the stiffness requirements, that is, under lateral loads, the structural horizontal displacement value and story displacement must meet the specified design specifications. Therefore, the structural system must simultaneously meet the requirements of bearing capacity and stiffness.

Current research focuses on the kind of theoretical model architecture, and often encountered relative displacement between the structural layer under the control of the earthquake, under rare earthquake structural damage form, etc., but this architecture seismic weak position (eg node 
structural measures steel frame beam and reinforced concrete core-tube in contact) study, and improve seismic studies defense issues such as not comprehensive enough, most of the current research literature focused on the study of the properties of the beam wall hinged node on the relevant girder wall rigid joint research is still rare reports.

According to the above discussion, steel-concrete composite structure is one of the main structural forms in the future high-rise building applications, and the current domestic research on this structural type is imperfect. Based on previous studies, this paper focuses on an experimental study of loaded property and seismic performance of steel beam-concrete wall rigid joint specimen under the low-cycle reversed loading test, and specific contents include:

1. This paper makes an experimental study of three steel beam - concrete wall rigid joint specimens under the low-cycle reversed loading test, focuses on analyzing the failure form, bearing capacity, ductility, hysteresis behavior and force condition of node core region and strain distribution of key parts;

2. This paper compares the bearing capacity with seismic performance of node specimen with different bolt diameter and different joint thickness;

3. This paper introduces the application conditions and basic principle of fiber grating sensing technology in the civil engineering field, and discusses the feasibility and realization approach for the application of brag grating sensor in the civil engineering detection.

\section{Steel Beam - Concrete Wall Rigid Joint Experiment}

Steel material experiment is unidirectional tensile test, which is primarily used to determine the mechanical properties of steel in the unidirectional tensile state, such as steel elasticity modulus $\mathrm{E}_{\mathrm{s}}$, yield stress $\sigma_{\mathrm{y}}$, tensile strength $\sigma_{\mathrm{u}}$ elongation rate $\delta$, and provides relevant parameters for the analysis of test results. Steel tensile specimen is a plate specimen and rough specimen selection and processing shall comply with relevant specifications. Steel grade is Q235, all material specimens shall adopt the same steel with the beam wall node specimens, produce in the same time, and there shall be three specimens with each thickness of steel. Paste the strain gauge in the central of specimen in the specimen longitudinal direction, the specimen deformation shall be determined by strain gauge, and the tensile test is carried out on a tensile machine. For specimen, please refer to Diagram 1 .

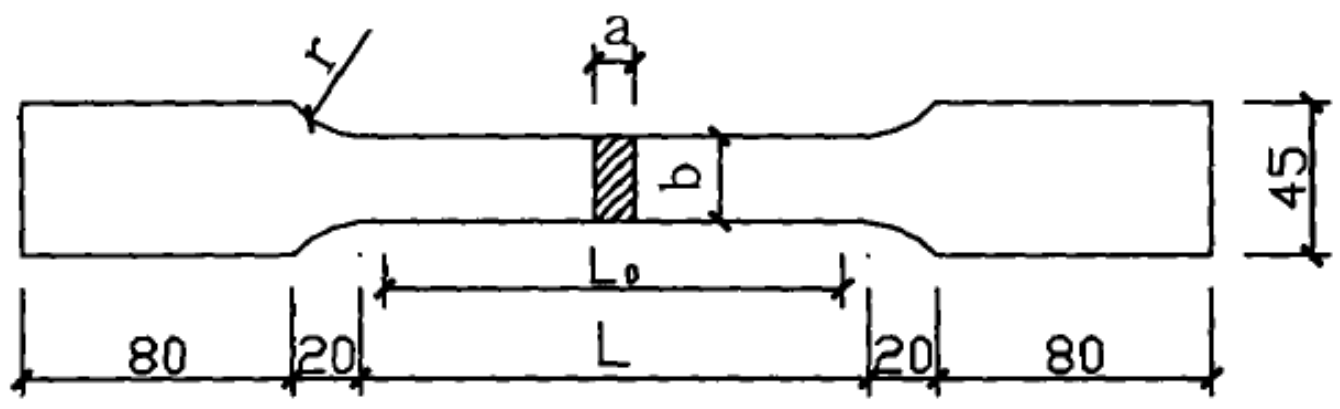

Fig. 1 Diagram of Steel Material Property Experimental Specimen Processing

The most ideal experimental condition is to use the analog seismic shaking table for power test. However, because of the expensive investment in equipment, complex management technology, shaking table experiment failure due to oversize test object and other factors, a large amount of 
domestic and foreign structural seismic experiments make use of low cycle and iterative static test for load simulation. Test method of low cycle reversed loading refers to the assumption that imposes force or displacement under the low-cycle reversed loading action over test object in the first vibration mode condition. Since each loading cycle when low cycle reversed loading is far greater than the basic structural cycle, it is static loading method that conducts the approximate simulation of seismic action.

\section{Experime ntal Research and Theoretical Analysis of Rigid Joint between Steel Beam - Concrete Wall}

According to the analysis of the above failure form, three node specimens do not show enough ductility, the ultimate failures of each node specimen are caused by welded seam tension. It is difficult for the welded seam to develop plastic, so it belongs to brittle failure mode. Ideal failure should be: The beam end first yields to form plastic hinge, the external load reaches the steel ultimate tensile strength and pull off, and there should not be welded seam failure caused by strain concentration, material damage and other factors. In the failure, it can be found that the bottom flange of steel beam yields, and the plate does not yield, indicating that before specimen failure, the load is mainly undertaken by the welded seam and steel beam flange, the steel beam plate and joint plate do not fully play its material strength, and the collaboration work performance is weak. Bolt slip appears in the plastic phase. When the bolt slips, it is accompanied by intense sound, and several loud noises will be sounded every load, indicating that bolt slip does not occur simultaneously, the multiple times of violent shake that the bearing capacity suddenly decreases and rapidly rises in the curve record. When the welded seam pulling off becomes a failure, bolt connection can still work better. Beam end will not be completely fallen off. There was no damage for the concrete near nodes, indicating that the node domain bearing capacity has great potential reserves.

The loading property of steel beam - concrete wall composite node is different from the reinforced concrete structure and steel structure, and there is no uniform guideline for the determination of composite node yield and failure. To facilitate analysis and comparison, this paper adopts "general yield moment method" (G.Y.M.M) to determine the yield point of specimen, and the principle is shown in Fig. 2. The load displacement curve without apparent yield point (inflection point) is shown in Fig. 3. Split the coordinate origin - point 0 as the tangent line of p- $\Delta$ curve and intersect with the horizontal line of highest load point at point B, make a perpendicular line at point B, cross p- $\Delta$ curve at point $\mathrm{A}$, connect with the extension line, cross line $\mathrm{DB}$ at point $\mathrm{C}$, make a perpendicular line at point $\mathrm{A}$ and $\operatorname{cross} \mathrm{p}-\Delta$ curve at point $\mathrm{E}$, then point $\mathrm{E}$ is the yield point, and the corresponding coordinate is yield load $\left({ }^{P_{y}}\right)$ and yield displacement $\left(\Delta_{\mathrm{y}}\right)$. 


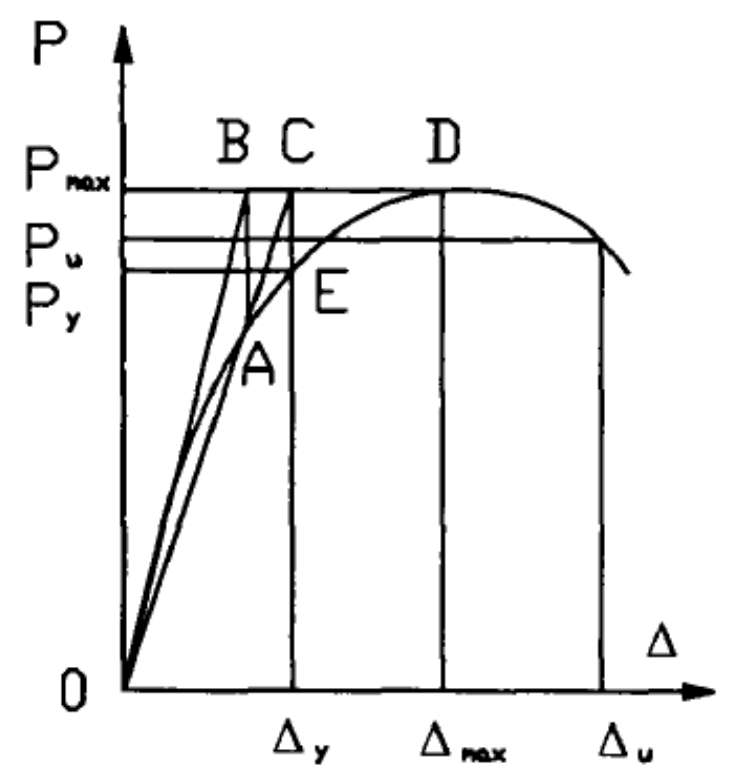

Fig. 2 Determination of Specimen Yield Point

\section{Application of Fiber Grating Sensor in Experiment}

Fiber is the optical fiber for short. It is a dielectric waveguide working in the light wave band, which is usually of round rectangle. It can restrain the electromagnetic wave in the form of light to its interface by using the principle of total reflection, and guide the light wave to move forward in the direction of optical axis. By the quantity of transmission mode, the fiber can be divided into single-mode fiber and multi-mode fiber. Single-mode fiber is often used to make the grating and its core diameter is $2 \mathrm{um}$ to $12 \mathrm{um}$. The fiber grating length is affected by the process, which does not exceed $2 \mathrm{n} 5 \mathrm{~m}$ generally (long grating is deeply affected by external factors). From the aspect of cyclic structure, grating is divided into regular cycle and variable cycle. Brag grating sensor uses the grating with regular cycle. The grating cycle is generally $0.05 \mathrm{~nm} \sim 0.3 \mathrm{~nm}$.

Fiber grating sensing technology is the absolute measurement to realize the strain and temperature value of measured structure through the grating reflection by writing into the fiber or the detection of transmission brag wavelength spectrum. The reflection of fiber grating or transmission brag wavelength spectrum is mainly determined by the grating period A and effective reflection rate of reverse clamping mold, and any physical process making the changes in two parameters will lead to brag grating wavelength drift, that is:

$$
\lambda_{\mathrm{B}}=2 \mathrm{n}_{\mathrm{eff}} \cdot \mathrm{A}
$$

Where, $\lambda_{\mathrm{B}}$ is the center wavelength of fiber grating; $\mathrm{A}$ is fiber grating cycle; $\mathrm{n}_{\text {eff }}$ the effective refractive index of optical fiber. In all external factors causing brag grating wavelength drift, the most direct is strain parameter, because regardless of grating stretching or compressing, it is inevitably lead to changes in the grating period A, and the elasto-optical effect of the fiber itself also makes the effective refractive index change with the changes of external strain state, which provides the most basic physical property to produce the fiber optic strain sensor by using the fiber brag grating. 
Based on the above several assumptions, this paper may respectively obtain the wavelength drift formula caused by axial stress and temperature changes. For the brag grating wavelength drift caused by stress and strain, see the below expression:

$$
\Delta \lambda_{\mathrm{B}}=\left(1-\mathrm{P}_{\mathrm{e}}\right) \bullet \varepsilon \bullet \lambda_{\mathrm{B}}=k_{\varepsilon} \bullet \varepsilon \bullet \lambda_{\mathrm{B}}
$$

Where, $\Delta \lambda_{\mathrm{B}}$ is the wavelength caused by strain, and it is only the effective elastic coefficient of fiber, which can be expressed as:

$$
P_{e}=\left(n_{\text {eff }}^{2} / 2\right)\left[P_{11}-v\left(P_{11}+P_{22}\right)\right]
$$

Therefore, it is featured by high measurement sensitivity, only needs to detect the accurate location of wave crest the center grating wavelength distribution diagram of fiber, which is unrelated with light intensity, insensitive to the light intensity fluctuation, and has higher anti-interference ability than general fiber sensor.

\section{Conclusions}

This paper studies the node seismic performance of rigid joint between steel beam - concrete wall under the low-cycle reversed loading test, focuses on analyzing the failure form, hysteretic curve features, rigid change, bearing capacity, ductility, strain of key parts of each node specimen and moment delivery mechanism under the low-cycle reversed loading test, compares with the node seismic performance with different bolt diameter and joint plate thickness; and makes a comparison experiment, discusses the feasibility and realization method for the application of brag grating sensor in the civil engineering detection. According to the experimental and theoretical analysis, this paper comes to the following conclusions:

1. The ductility and energy dissipation of three node specimens in this experiment can meet the seismic design requirements;

2. The bolt specification has a large impact on the bearing capacity and seismic performance of node specimens: when increasing its specification, the node bearing capacity and seismic performance will be increased accordingly, and vice versa;

3. The bearing capacity and seismic performance of node specimens are slightly increased with the increase in joint thickness, indicating that the increase in joint thickness is favorable for improving the bearing capacity and seismic performance within a certain range, but the impact is not obvious;

4. Concrete distribution reinforcement do not yield much, reinforce by the structure in design, the concrete pressure stress at both sides of dark bracket flange is small, and the impact of external load will not be considered in design;

5. Node connection type can ensure to transmit load to bracket through the steel beam, which is an effective guarantee for the realization of rigid joint;

6. The feasibility of fiber grating sensor application in the civil engineering detection is verified by comparing the strain value measured by fiber grating sensor and resistance strain gauge.

Although this paper has achieved certain results, many aspects need further analysis and discussion due to little specimen, and the further study and suggestions are as following: 
1. The experiment shows that it is easy for the welded seam to occur brittle failure under the cyclic loads, so how to reduce the transmission of seismic energy to the welded seam and delay the welded seam to occur brittle failure need to be further studied;

2. This paper only considers the impacts of bolt specification and joint thickness on the node seismic performance, and future study may consider the impacts of other factors on its performance, such as steel beam flange thickness and bolt arrangement method;

3. Based on the study of loaded property of steel beam - concrete wall node, this paper shall further explore the impact of node performance on seismic performance of the entire structural system.

\section{Acknowledgment}

This work was supported by Project on professional and characteristical construction of Jiangxi province 2010 (Civil Engineering) and Project on the planning and construction of disciplines in Jiangxi University of Technology (Structure Engineering)

\section{References}

[1] Roeder C W. Overview of hybrid and composite systems for seismic design in the United States[J]. Engineering structures, 1998, 20(4): 355-363.

[2] Lai W, Tie-cheng W, Qian C. Experimental study on seismic performance of concrete-filled rectangular tubular frame under low-reversed cyclic loading $[\mathrm{J}][\mathrm{J}]$. Earthquake Engineering and Engineering Vibration, 2003, 3:017.

[3] Chen J F, Teng J G. Anchorage strength models for FRP and steel plates bonded to concrete[J]. Journal of Structural Engineering, 2001, 127(7): 784-791.

[4] LU X, LU W. Seismic Behavior of Concrete-filled Rectangular Steel Tubular Columns Under Cyclic Loading [J]. Journal of Building Structures, 2000, 2: 000.

[5] Han L H, Li W. Seismic performance of CFST column to steel beam joint with RC slab: Experiments[J]. Journal of Constructional Steel Research, 2010, 66(11): 1374-1386.

[6] Ricles J M, Peng S W, Lu L W. Seismic behavior of composite concrete filled steel tube column-wide flange beam moment connections[J]. Journal of Structural Engineering, 2004, 130(2): 223-232.

[7] Pampanin S. Emerging solutions for high seismic performance of precast/prestressed concrete buildings[J]. Journal of Advanced Concrete Technology, 2005, 3(2): 207-223.

[8] Ghobarah A, Aziz T S, Biddah A. Rehabilitation of reinforced concrete frame connections using corrugated steel jacketing[J]. ACI Structural Journal, 1997, 94(3).

[9] Wang J C, Ou Y C, Chang K C, et al. Large - scale seismic tests of tall concrete bridge columns with precast segmental construction[J]. Earthquake Engineering \& Structural Dynamics, 2008, 37(12): 1449-1465.

[10] Paulay T, Binney J R. Diagonally reinforced coupling beams of shear walls[J]. ACI special publication, 1974, 42. 